\title{
Holistic Model for Guiding Good Design Quality in Learning Multimedia Design Development
}

\author{
Edy Jogatama Purhita ${ }^{1, *}$ Eko Sediyono ${ }^{2}$ Ade Iriani $^{2}$ \\ ${ }^{1}$ University, Graphic Design Department, University of Science and Computer Technology, 50192, Indonesia \\ ${ }^{2}$ Faculty of Information Technology, Satya Wacana Christian University, 50715, Indonesia \\ *Corresponding author. Email: edyjogatama@stekom.ac.id
}

\begin{abstract}
Development of electronic learning (E-learnings), learning resources are teaching materials and a variety of information developed and packaged in various forms based on information and communication technology and used in the learning process. For this reason, special techniques for subject design, techniques are needed. specific learning, special methodologies through various media, and special organizational and organizational arrangements. In multimedia learning, the design process requires design methods, development tools, inspection models and skills in Information Technology systems. It is necessary to formulate a Holistic Method which considers all related aspects in order to guide the quality of good design in designing Multimedia Learning. Implementing the findings of the Holistic Method formulation to build multimedia learning with good design quality. This study formulates the stages of multimedia development which include: Creative Brief, Design, Material Preparation, Scripting, Testing, Distribution. The multimedia software development process will be guided by 15 guiding elements which are grouped into 5 elements. CONTENT first guiding element include : Perception of meaning, Information Message, Storytelling. APPEARANCE second guiding elements include : Aesthetic expression, Symbolic value, Material Medium. UTILITY ASPECT third guiding element include : Engineering Quality, Usability, Navigation Structure. USER CARACTER fourth guiding element include : Biophysic, Psycho, Sosio Culture. DIDACTIC fifth guiding element include : Learning situation, Pedagogical strategy, Personalization. These guiding elements are used to produce good quality learning multimedia designs. The methodology is called Holistic Multimedia Development Model (HMDM).
\end{abstract}

Keywords: Design, Multimedia, Learning Technology

\section{INTRODUCTION}

Technological advances penetrate all fields, especially in education. Computer laboratories seem to be mandatory, as part of the educational infrastructure. Students and school students almost all hold technology devices in the form of smartphones. Equipment that is not only used for communication, but also to access information for their learning needs. The government is in a massive effort to make high-speed Internet affordable and a source of free online teaching. Even so that it can be reached by the most remote schools in rural areas. Although significant research results have also confirmed that most teachers are slow to change the way they teach, in adapting to the entry of new technology into their classrooms. Some research results also show that technology and online learning improve learning outcomes for most students.
The current Indonesian government policy in improving the quality of education is to develop information technology-based education. This is an effort to increase equitable access to higher education in Indonesia through Distance Education Program (PJJ) and E-learning. The community can further access and facilitate higher education services in education and learning. Individual/independent or group learning using ICT and networks can be combined with face-to-face learning/blended learning. The application of learning technology that has innovative value provides new nuances in the teaching and learning process that is different from ordinary face-to-face learning.

Development of electronic learning (E-learnings), learning resources are teaching materials and a variety of information developed and packaged in various forms based on information and communication technology and used in the learning process. For this reason, special 
techniques for subject design, techniques are needed. specific learning, special methodologies through various media, and special organizational and organizational arrangements. The teaching and learning process can be carried out outside the classroom by using specially designed teaching materials to replace the face-to-face learning or lecture process in accordance with the instructional objectives set, it needs to be designed and organized systematically with the help of appropriate communication media.

But what needs to be considered is that the presentation of multimedia learning must be adjusted to the specified learning objectives to facilitate the learning process, because learning activities are a system that contains components that are interrelated or connect with one another. In addition to the factors related to the learning process which are the topic of discussion in multimedia learning, the design process of course requires design methods, development tools, examination models and skills in Information Technology systems.

\section{METHOD}

This study identifies aspects that guide good design quality when designing multimedia learning materials and validates these principles from the perspective of designers (software developers), students and lecturers, the learning process, as well as aspects that are expressed and implied in multimedia learning computing products. Also, the factors inhibiting the use of multimedia learning and the steps taken to overcome them were studied. Data was collected from stakeholders in a multimedia assisted learning environment in a higher education environment. Mixed methods including interviews, surveys and group discussions are used to collect qualitative data, Mixed methods are used to collect data to improve triangulation.

Search and collect research data about learning multimedia development methods and their designs from online articles and university library research reports. Equipped with in-depth interviews, namely data collection by conducting in-depth interviews with key informants (multimedia designers, lecturers). The data obtained will be analyzed, and then the analysis will be enriched through a focus group discussion (FGD) that involved the Graphic Design Department of the Computer Science \& Technology University and the Information Technology Faculty of Satya Wacana Christian University (SWCU) Salatiga. The study will produce a holistic method formulation of multimedia learning development.

\section{RESULT AND DISCUSSION}

\subsection{Presenting the Results}

This research produces a new frame work, in which guiding aspects are formulated in order to produce good design quality, in guiding the stages of developing Learning Multimedia software. Aspects that can guide the creation of good quality design are identified. These aspects are understood by concepts, criteria, principles, and are applied in a strategy to create good design quality in every stage of multimedia learning development (Figure 1).

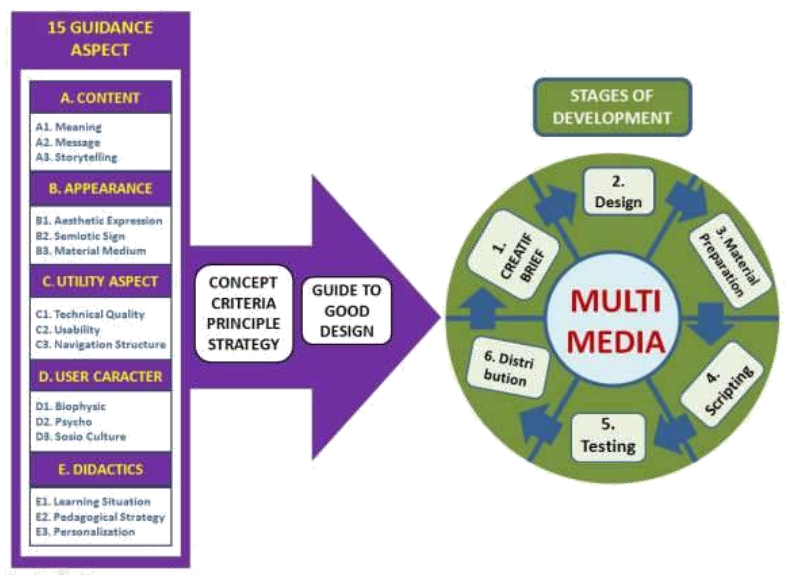

Figure 1 Guiding Elements of the multimedia development stage

The formulation of a Holistic Method framework that considers all related aspects in order to guide the quality of good design (good design) in the design of Learning Multimedia, depicted in Figure 2 :

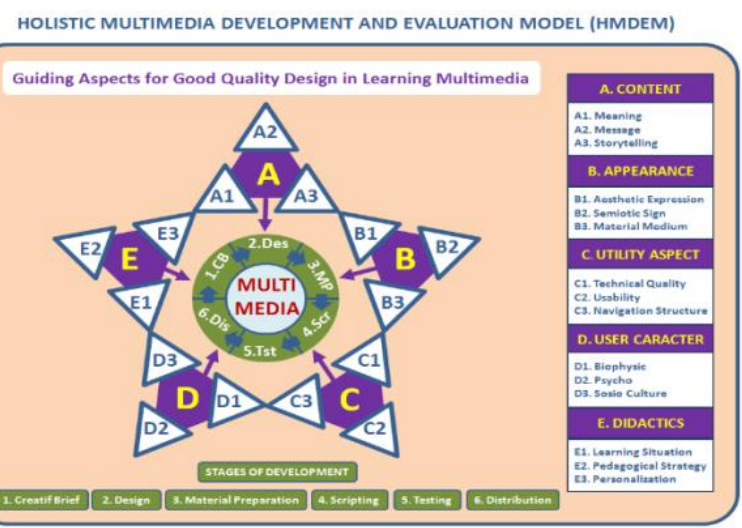

Figure 2 Holistic Model Framework to guide good design quality in the design of multimedia learning.

\subsection{Discussion}

Roblyer \& Doering [1] states that "multi media" or "combination of media", can be in the form of images and photos, sound, motion video, animation, and / or text items that are combined in a product. Multimedia is the use of various presentation tools techniques for convey 
information and is used to communicate with students [2]. Instructional multimedia is educational communication that uses words and graphics, can be presented in books, in live slide show presentations, in elearning on computers, or even in video games or virtual reality [3]. Thus, the complexity of multimedia can range from a combination of text and static graphics $[4,5]$ to a combination of text, audio files, and video files [6,7 and multiple web pages [8]. Multimedia learning can involve combination of verbal and image representations at various levels of complexity [9]. The characters of each material are different, the combination must be mutually exclusive inergy towards the learning objectives. Too many combinations of media and including irrelevant material should be avoided. According to Cavanaugh [10] multimedia can be defined as 'computer-mediated information that is presented simultaneously in more than one medium'. This refers to the existence of visual and verbal material [11]. Visual material can consist of static elements such as images or dynamic elements such as videos and animations, which are graphic elements that represent the phenomena of reality. Meanwhile, verbal material can consist of printed and spoken words [12]. Irrelevant informational messages should be excluded from the presentation [13].

Effective multimedia design can improve students' ability in cognitive processing and absorb and assimilate learning materials [14]. Well-designed multimedia can create an engaging and instructive learning experience. Effective design helps students pay attention to relevant information, organize it into a coherent mental representation, and integrate it with previous knowledge. But research also shows that poorly designed material has a negative impact because too much irrelevant information can overwhelm learners [15].

People have the ability to integrate information from various sensory modalities such as the eye; ears and nose to create meaningful experiences. Therefore, instructional designers are faced with the need to choose between multiple combinations of modes and modalities to promote meaningful learning [16]. According to Mandernach [17] students have limited working memory and are reserved for understanding learning content, rather than being used to coordinate various visual components. The embodiment of a unity design and easy and clear navigation will make it easier for students to absorb learning content. Unnecessary verbal or visual information should be eliminated, because it can distract students from focusing, distracting their concentration on irrelevant information can ignore important information. This will hinder learning because it interferes with information integration.

Visual and verbal information are used to represent information in the minds of learners [18] and are processed simultaneously. Research shows that students who learn with narrative and animation at the same time outperform those who learn with text and animation on the screen simultaneously [19]. According to cognitive processing theory, students are only able to process a small amount of information. Too much information or information presented is unclear or irrelevant, can lead to cognitive overload which has a negative impact on learning [20].

The personalization aspect makes designers have to promote deeper engagement with students. Learning materials are created that can create psychological relationships with students. Strategies for doing this include using colloquial language rather than a formal style. Make effective use of screen guides or avatars that represent the teacher in delivering learning. Research has found that students learn better when the content is conversational, than when it is delivered in a formal approach. This strengthens the effect of socialization between teachers and students. Reeves and Nass [21] stated that students' motivation increases and they work harder to understand the material when they engage in the 'social interaction effect' using personalized material.

From the above discussion, considerations to improve the quality of learning multimedia designs are formulated as guide elements. The guiding elements include 15 guiding elements grouped into 5 aspects, namely:

A. CONTENT : Perception of meaning, Information Message, Story telling.

B. APPEARANCE : Aesthetic expression, Symbolic value, Medium Material.

C. UTILITY ASPECT: Engineering Quality, Usability, Navigation Structure.

D. USER CHARACTER : Biophysic, Psycho, Socio Culture.

E. EDUCATIONAL ASPECTS (DIDACTICS): Learning situation, Pedagogical strategy, Personalization

Designing or designing instructional media in a multimedia format based on Information Technology requires a specially designed method. This is so that the final result can be approved for validation of good quality design results. In the software engineering domain, the software development life cycle (SDLC) can be defined as a set of activities that lead to the production of a software product. In the same sense, the multimedia development life cycle (MDLC) can be defined as a set of activities that lead to the production of multimedia products. In general, SDLC includes four fundamental activities: software requirements specification, design and implementation, software validation, and evolution. This activity is mostly used to develop all types of software. MDLC for non-interactive multimedia products includes three fundamental activities: preproduction, production, and post-production. However, interactive multimedia product development integrates 
the three activities mentioned above with SDLC activities, because interactive multimedia products are software applications [22]. The MDLC (Multimedia Development Life Cycle) method is easier to understand and implement, the steps are clear and easy to follow, logically structured and sequential, and can be used by small software developers [23].

Experts have conducted research on multimedia software development methods, including: Luther, Godfrey, and Vaughan. Luther [24] defines the steps for developing multimedia software with 6 stages, namely: Concept, Design, Content Collection, Assembly, Testing, and Distribution. Each stage does not have to be sequential, but can be done in parallel with the planning stages (concept and design) must be started first. The method developed by Godfrey [25] is a derivative of the classic software development method known as Waterfall. He calls his method the Multimedia Development Life Cycle (MDLC) while the Waterfall method is called Godfrey with the Systems Development Life Cycle (SDLC). The two methodologies (SDLC and MDLC) simply use different terms, but actually do what can be said to be the same. The six stages in Godfrey's multimedia development are: Problem Definition, Genre and Character, Location and Interface, Plotting, Scripting, and Production and Testing. The stages of development (stage of development) multimedia learning in the Holistic Model include: 1. Creative Brief, 2. Design, 3. Material Preparation, 4. Scripting, 5. Testing, 6. Distribution. In order to create good quality learning multimedia designs, the design stages are guided by considering the 15 elements above.

\section{CONCLUSION}

Traditionally, learning is done face-to-face, where students interact directly with the teacher. Interpersonal interactions, humans interact with humans. It involves physical interactions, psychological interactions, social interactions. This interaction builds communication that carries the content of learning content, the transfer of knowledge from teachers to students occurs. A very complex process involving many factors.

During the pandemic face-to-face learning was not possible because of health protocols. Teachers and students cannot interact directly. So that teachers and students in order to be able to carry out the learning process, media is needed as a means that can connect the two in a distance of time and space differences. So the learning media that is designed must be able to build a distance learning process that can replace the face-to-face learning process which is very complex, as explained above.

Learning media is not just an information board. However, it can build virtual relationships with teachers who are not in front of students directly. It is not just a relationship between humans and machines or electronic media, it is not just a matter of engineering engineering. Learning media that are able to build a good learning process that is interactive, communicative, recreational, educational.

The Hoslistik Multimedia Development model provides guidance so that the instructional multimedia designers do not only think partially in their media design considerations. Overall aspects are taken into consideration in terms of media form, media content, media users, engineering and didactics. In this case we offer 15 guiding elements that can be used in designing good multimedia learning that can meet the needs and solutions of distance learning which are concrete solutions to educational needs in a pandemic.

\section{REFERENCES}

[1] Roblyer, M \& Doering, A.H., "Integrating Educational Technology Into Teaching", Boston: Pearson, 2010.

[2] Ramlatchan, M., "Multimedia learning theory and instructional message design". In M. Ramlatchan (Ed.), "Instructional Message Design: Theory, Research, and Practice" (Vol. 1). Norfolk, VA: Kindle Direct Publishing, 2019.

[3] Mayer, R. E., "How multimedia can improve learning and instruction", Cambridge University Press, p. 460-479, 2019.

[4] Acarturk, C., \& Ozcelik, E., "Secondary-task effects on learning with multimedia: An investigation through eye-movement analysis", The Journal of Experimental Education, 85, 126-14, 2017.

[5] Chiu, T. K. F., \& Mok, I. A. C., "Learner expertise and mathematics different order thinking skills in multimedia learning", Computers and Education, 107, 147-164, 2017.

[6] Andrade, J., Huang, W.-H. D., \& Bohn, D. M., “The impact of instructional design on college students' cognitive load and learning outcomes in a large food science and human nutrition course", Journal of Food Science Education, 14, 127-135, 2015.

[7] Chung, S., Cheon, J., \& Lee, K. -W., "Emotion and multimedia learning: An investigation of the effects of valence and arousal on different modalities in an instructional animation", Instructional Science, 43, 545-559, 2015.

[8] Cheng, T. S., Lu, Y. C., \& Yang, C. H., "Using the multi-display teaching system to lower cognitive load", Educational Technology and Society, 18, 128-140, 2015. 
[9] Anmarkrud, Ø., Andresen, A., \& Bråten, I., "Cognitive load and working memory in multimedia learning: Conceptual and measurement issues", Educational Psychologist, 54(2), 61-83, 2019.

[10] Cavanaugh, C.S., “The Effectiveness of Interactive Distance Education Technologies in Secondary learning: A meta-analysis", International Journal of Educational Telecommunications 7, p. 73-88, 2001.

[11] Jonassen, D.H., Howland, J., Moore, J., Marra, R.M., "Learning to Solve Problems with Technology: A Constructivist Perspective (2nd Edition)", 2002.

[12] Issa, N., Mayer, R.E., Schuller, M., Wang, E., Shapiro, M. B. and DaRosa, D.A., "Teaching for understanding in medical classrooms using multimedia design principles", Medical Education 47, p. 388-396, 2013.

[13] Warren Davies dan Kathryn Cormican, “An Analysis of the Use of Multimedia Technology in Computer Aided Design Training : Towards Effective Design Goals", Procedia technology 9 P. $200-208,2013$.

[14] Moreno, R., Mayer, R.E., "A coherence effect in multimedia learning: The case for minimizing irrelevant sounds in the design of multimedia instructional messages", Journal of Educational Psychology, 97, p. 117-125, 2000.

[15] Mayer, R., "Multimedia Learning", Cambridge University Press, New York, 2001.

[16] Issa, N., Schuller, M., Santacaterina, S., Shapiro, M., Wang, E., Mayer, R.E., DaRosa, D.A., “Applying multimedia design principles enhances learning in medical education", Medical Education, 45, 8, p. 818-26.208 2011, 2011.
[17] Mandernach, B.J., 2009. Effect of Instructor Personalised Multimedia in the Online Classroom. International Review of Research in Open and Distance Learning, 10, 3.

[18] Nelson, B.C., Ketelhut, D.J., Younsu, K., Foshee, C., Slack, K., "Design Principles for Creating Educational Virtual Worlds" In "Emerging Technologies for the Classroom" C. Mouza and N. Lavigne, Editors, Springer, New York, p. 205-222, 2013, 2013.

[19] Clark, R.C., Mayer, R.E., "E-Learning and the science of instruction: proven guidelines for consumers and designers of multimedia learning", Jossey-Bass/Pfeiffer Edition.

[20] Moreno, R., "Decreasing cognitive load for novice students: Effects of explanatory versus corrective feedback in discoverybased multimedia", Instructional Science, 32, 99-113, 2004.

[21] Reeves, B., Nass, C., The Media Equation, Cambridge University Press, New York, 1996.

[22] Al-Jabari, M., Tamimi, T., \& Ramadan, A. A., "Multimedia Software Engineering Methodology A Systematic Discipline for Developing Integrated Multimedia and Software Products", Software Engineering, 8(1): 1-10, 2019.

[23] Setyadi, R., \& Ranggadara, I., "Augmented reality using features accelerated segment test for property catalogue", Telkomnika, 18(1), 2020.

[24] Luther, A. C., "Authoring Interactive Multimedia", Academic Press,Inc., Massachusettes, 1994.

[25] Godfrey, R., "New Wine in Old Bottle: Multimedia Design Methodology”, ASCILITE '95, Melbourne, Australia, 1995. 